\title{
Criginal Evaluation of gastroesophageal reflux after laparoscopic cholecystectomy using combined impedance-pH monitoring
}

\author{
Rigved Gupta, Gaurav Kochhar, Ashok Kumar, Sudipta Saha, Manoj \\ Andley, Rahul Pusuluri, Gyan Saurabh, Ajay Kumar
}

\begin{abstract}
Department of Surgery,

Background and aim: Postoperative gastroesophageal reflux (GER) is one of the causes of Lady Hardinge Medical College,

New Delhi, India

Correspondence:

Dr. Gaurav Kochhar post-cholecystectomy syndrome (PCS). Reports studying the effect of cholecystectomy on GER show conflicting results and only a few studies have used the more sensitive technique of combined impedance-pH monitoring. This study aimed to study the effect of laparoscopic cholestectomy on GER (acid/ non-acid reflux) using impedance-pH monitoring.

Email: gauravkochhar82@gmail.com Methods: Sixty three consecutive patients of symptomatic cholelithiasis were evaluated. All patients underwent esophageal mannometry and 24-hour impedance-pH monitoring pre- and postoperatively. Frequency scale for the symptoms of GERD (FSSG) scoring was also done in each patient pre- and postoperatively.

Results: Out of sixty three patients, four developed symptoms of reflux postoperatively as detected by FSSG scoring. However, no significant changes were observed in lower esophageal sphincter (LES) characteristics, acid and non-acid reflux characteristics, total number of reflux episodes, or in the physical character of the refluxate following laparoscopic cholecystectomy. Significant decrease in the proximal acid reflux episodes was observed.

Conclusion: The chemical characteristics (acid or non-acid reflux) as well as physical properties (liquid, gas or mixed) of reflux episodes remain unaffected following laparoscopic cholecystectomy. Cholecystectomy itself doesn't increases GER.
\end{abstract}

KEYWORDS: FSSG score, gastroesophageal reflux, impedance-pH manometry, postcholecystectomy syndrome

\section{Introduction}

Laparoscopic cholecystectomy (LC) is currently considered to be the gold standard for treatment of symptomatic gallstone disease as it causes minimal postoperative pain, has better cosmetic results, and is associated with early return to work. ${ }^{1}$ Post-cholecystectomy syndrome (PCS) is one of the complications of cholecystectomy and is defined as a complex of heterogeneous symptoms, consisting of dyspepsia, flatulence, bloating, bitter taste, heartburn and epigastric/ right upper quadrant pain, which recur and/or persist after cholecystectomy. ${ }^{2}$ The postulated etiologies for this syndrome includes gastroesophageal reflux, retained common bile duct stones, inflammation of the cystic duct remnant, and sphincter of Oddi dysfunction. ${ }^{3}$

Studies examining the effect of cholecystectomy on GER 
show conflicting results. Majority of the studies report an increase in post-cholecystectomy GER (acid/non-acid reflux) in terms of frequency and extent. ${ }^{4,5}$ However, there are also studies, which shows no change. ${ }^{6,7}$ In 1991, Silny was the first investigator who described multichannel intra-luminal impedance (MII), a technique which detects intra-esophageal bolus transport by measuring the resistance to alternating current (i.e., impedance) of the content of the esophageal lumen. ${ }^{8}$ Combined MII and $\mathrm{pH}$ monitoring (MII-pH) allows evaluation of the nature (liquid/gas/ mixed), $\mathrm{pH}$ (acid/weakly acid/ non-acid), proximal extent, direction and the duration of reflux event. ${ }^{9}$ Traditional $\mathrm{pH}$ monitoring comments only on the $\mathrm{pH}$ of refluxate and does not provide any other information. The use of combined Impedance-pH monitoring, thus increases the diagnostic yield compared to $\mathrm{pH}$ monitoring alone and is considered to be the most sensitive tool for assessing all types of GER (acidic, weakly acidic and weakly alkaline). ${ }^{10,11}$ This study was conducted to determine the effect of laparoscopic cholecystectomy on GER (acid/ non-acid reflux) using impedance $-\mathrm{pH}$ monitoring.

\section{Methods}

This prospective study was conducted at a tertiary care centre in New Delhi, India, from November 2011 to March 2013. The study was approved by the hospital ethical committee and an informed consent was taken from all patients enrolled into the study. Sixty three consecutive patients, who underwent laparoscopic cholecystectomy with a diagnosis of symptomatic cholelithiasis supported by abdominal ultrasonography, were included in the study. Patients with co-existent diseases which precluded esophageal functional studies or effected LES tone were excluded e.g. scleroderma, peptic ulcer, achalasia cardia, myopathies, hyperthyroidism or hypothyroidism. Also patients who had undergone previous upper gastrointestinal tract surgery or patients on drugs which affect LES tone (calcium channel blockers, aminophylline, nitrates/nitroglycerine, opioids, benzodiazepines, oral contraceptive pills, anticholinergics, non-steroidal anti-inflammatory drugs, steroids, potassium supplements, thyroxine, prokinetics) were excluded from the study.

$\mathrm{H}_{2}$ receptor antagonists and prokinetic drugs were stopped two days before the study and proton pump inhibitors (PPIs) were stopped 14 days before the study in all patients. Patients were advised to avoid smoking, alcohol, aerated drinks and other spicy food during the period of observation. FSSG scoring was done on every patient. The patients underwent preliminary esophageal manometry to identify the site of lower esophageal sphincter and the resting LES pressure. After identification of the position of the LES, patients were then evaluated one day prior to surgery by combined 24 hour ambulatory MII $-\mathrm{pH}$ monitoring,.

Reflux episodes were classified into: a) liquid only, if fall in impedance was noticed in all channels; b) gas only, if impedance values rose in all channels; or c) mixed (liquid-gas, gas-liquid), if a combination of the two patterns were noted. By measuring impedance at multiple levels in the esophagus, the height or proximal extent of the reflux was also determined. Episodes were considered to extend into the proximal esophagus, if impedance changes indicative of liquid were identified at 15 $\mathrm{cm}$ above the LES. All the patients then underwent laparoscopic cholecystectomy under general anaesthesia. Repeat esophageal manometry and 24-hour ambulatory impedance$\mathrm{pH}$ monitoring using the same procedure for calculating postoperative parameters was done six months after the surgery.

Statistical analysis was carried out for LES pressure and percentage LES relaxation; acid reflux - including acid exposure time, acid exposure percent time, total acid reflux episodes, and the DeMeester's score; non-acid reflux - including non-acid exposure time, non-acid exposure percent time, total non-acid reflux episodes; nature of refluxate (total number of liquid, gaseous and mixed refluxes); number of proximally extending refluxes (15 $\mathrm{cm}$ above LES); and FSSG scoring.

The impedance/pH reflux monitoring was carried out using the $\mathrm{ZepHr}^{\circledR}$ impedance/pH system. The system included a ZepHr Z/pH recorder, ZepHr Z/pH catheters, pouch, SD card and battery. The system measures impedance to detect reflux activity and uses $\mathrm{pH}$ to categorize each episode as acid or non-acid. Data analysis was carried out using the BioVIEW ${ }^{\circledR}$ ZepHr analysis and recording software.

\section{Results}

Sixty three patients were evaluated during the study period. Their age ranged from 19 to 66 years with a mean age of 36.6 $(\mathrm{SD}=8.3)$ years. Out of a total of 63 patients, $54(85.7 \%)$ were females and $9(14.3 \%)$ were males. The various parameters monitored in the study included preoperative and postoperative FSSG score, basal LES pressures (mm $\mathrm{Hg}$ ), percentage LES relaxation, acid exposure time, total number of acid reflux episodes, non-acid exposure time, non-acid reflux episodes, total number of reflux episodes, total number of liquid 
Table 1: Preoperative and postoperative characteristics of study patients

\begin{tabular}{|c|c|c|c|}
\hline Variables & Mean pre op values \pm SD & Mean post op values \pm SD & p value \\
\hline \multicolumn{4}{|l|}{$\underline{\text { LES characterstics }}$} \\
\hline - Basal LES pressure (mm Hg) & $21.12 \pm 7.33$ & $20.25 \pm 7.27$ & 0.015 \\
\hline - Percent LES relaxation & $78.86 \pm 13.20$ & $82.58 \pm 13.54$ & 0.152 \\
\hline \multicolumn{4}{|l|}{ Acid reflux characterstics } \\
\hline - Acid exposure time (mintues) & $6.05 \pm 4.07$ & $5.68 \pm 3.89$ & 0.693 \\
\hline - Acid reflux episodes & $16.25 \pm 8.36$ & $16.37 \pm 9.25$ & 0.805 \\
\hline \multicolumn{4}{|l|}{ Non acid reflux characterstics } \\
\hline - Non-acid exposure time (minutes) & $4.58 \pm 2.91$ & $4.13 \pm 3.07$ & 0.157 \\
\hline - Non-acid reflux episodes & $18.11 \pm 2.91$ & $15.75 \pm 6.36$ & 0.225 \\
\hline \multicolumn{4}{|l|}{ Total reflux episodes } \\
\hline - Total acid and non-acid reflux episodes & $34.37 \pm 11.95$ & $32.11 \pm 10.60$ & 0.141 \\
\hline \multicolumn{4}{|l|}{$\underline{\text { Physical characterstics of reflux episodes }}$} \\
\hline - Liquid and mixed reflux episodes & $29.94 \pm 10.29$ & $28.40 \pm 9.12$ & 0.228 \\
\hline - Gaseous reflux episodes & $4.33 \pm 1.69$ & $4.02 \pm 1.51$ & 0.303 \\
\hline \multicolumn{4}{|l|}{ Proximally extending reflux episodes } \\
\hline - Proximal acid reflux episodes & $10.27 \pm 6.57$ & $8.01 \pm 7.92$ & 0.003 \\
\hline - Proximal non-acid reflux episodes & $8.10 \pm 5.20$ & $8.81 \pm 4.50$ & 0.256 \\
\hline - Total proximal episodes & $18.37 \pm 8.11$ & $16.68 \pm 8.53$ & 0.294 \\
\hline \multicolumn{4}{|l|}{ Composite score } \\
\hline - Demeester's score & $4.93 \pm 4.67$ & $6.12 \pm 4.44$ & 0.041 \\
\hline
\end{tabular}

and mixed reflux episodes, total number of gaseous reflux episodes, proximal acid reflux episodes, proximal non-acid reflux episodes, total number of proximal reflux episodes (acid and non-acid) and the DeMeester's score. The values for these variables were recorded both preoperatively and postoperatively. The results were analysed statistically using the Wilcoxon signed-ranks test and are depicted in Table $\mathbf{1 .}$

As per the FSSG scores none of the patient had symptoms of reflux preoperatively. The mean score was 1.936 and the standard deviation was 1.045 . There was fall in the proximal acid reflux episodes from a mean value of $10.27(\mathrm{SD}=6.50)$ preoperatively to $8.02(\mathrm{SD}=7.62)$ postoperatively $(\mathrm{p}=0.003)$.

The DeMeester's score also increased from $4.93(\mathrm{SD}=5.67)$ preoperatively to a mean of $6.12(\mathrm{SD}=4.44)(\mathrm{p}=0.041)$. However, the increase in DeMeester's score postoperatively (mean 6.12) was not clinically significant since it was less than the normal value of DeMeester's score (i.e. <14.7). Postoperatively four patients had symptoms of reflux as per the FSSG scores. These patients however didn't have any significant changes on $24 \mathrm{hr}$ $\mathrm{pH}$ monitoring and impedance manometry. The results of analysis of all other variables were found to be statistically insignificant.

\section{Discussion}

Laparoscopic cholecystectomy has become the 'gold standard' for surgical management of symptomatic gallstone disease.
Although laparoscopic cholecystectomy offers several advantages, it is associated with some adverse effects. One common adverse effect is the post-cholecystectomy syndrome (PCS). PCS was first described in 1947 by Womack and Crider and is defined as a complex of heterogeneous symptoms, including dyspepsia, flatulence, bloating, bitter taste, heartburn and epigastric/right upper quadrant pain, which recur and/or persist after cholecystectomy. ${ }^{12}$ In majority of patients, the symptoms are mild and short lived, but 2-5\% experience frequent debilitating pain. ${ }^{13}$ Our understanding of PCS is still imperfect. Although different studies report variable incidence of PCS, it is estimated to afflict 5-30\% of patients undergoing laparoscopic cholecystectomy.

The FSSG scoring system devised by Kusano et al consists of a simplified questionnaire for evaluating the symptoms of gastroesophageal reflux disease (GERD). The 12 questions to which patients most often answered "yes" were selected, and were assigned scores (never as 0; occasionally as 1; sometimes as 2; often as 3; and always as 4) to produce a frequency scale for symptoms of GERD (FSSG). When the cut-off score was set at 8 points, the FSSG showed a sensitivity of $62 \%$, a specificity of $59 \%$ and an accuracy of $60 \%$. The score obtained using the questionnaire correlated well with the extent of endoscopic improvement in patients with mild or severe GERD. ${ }^{14}$

Duodeno-gastroesophgeal reflux (DGER) is considered to be one of the factors responsible for symptoms of PCS. The loss of reservoir function of gall bladder after cholecystectomy 
causes an increase in duodeno-gastric and gastroesophageal reflux due to constant supply of bile to the duodenum. ${ }^{15}$ Duodeno-gastric and gastroesophageal reflux can occur as a normal physiological event which may assume pathological role following cholecystectomy due to altered physiology. ${ }^{15}$ Another mechanism of increased reflux is the impairment of the pyloric mechanism after cholecystectomy resulting in pyloric incompetence and increased reflux. Bile reflux into the stomach is reported in $30-100 \%$ of patients after stomach surgery and $80-90 \%$ after gallbladder surgery. ${ }^{16}$ Another possibility is altered antero-duodenal motility after cholecystectomy, possibly because of a change in the neurohumoral axis. Although recent studies by Bagaria et al do not support this hypothesis. ${ }^{17}$ It has also been reported that bile reflux seems to act synergistically with an increased $H$. pylori infection after cholecystectomy. ${ }^{18,19}$

A multicentre study by Shay et al, in 60 healthy volunteers off acid suppressive therapy quantified several impedance and $\mathrm{pH}$ parameters and established normal values for this technique. Based on the 95th percentile as the upper limit of normal, they proposed normal total distal reflux to be total reflux events $\leq 73$, acid reflux events $\leq 55$, weakly acid reflux events $\leq 26$ and weakly alkaline reflux $\leq 1 .{ }^{20}$ Studies have shown that esophageal reflux is more common in cholecystectomy patients than in control population and it is suggested that duodeno-gastric reflux may play a significant role in the pathogenesis of PCS. ${ }^{4,15,21}$ However, other studies shows contrary results. Lin et al compared pre- and postcholecystectomy changes in reflux symptoms in a large controlled prospective observational study. This study showed that cholecystectomy does not lead to an increase in reflux symptoms. ${ }^{6}$ Manifold et al also reported that cholecystectomy does not result in increased bile reflux into the stomach or increased gastroesophageal acid reflux. Those patients who had increased postoperative duodenogastric reflux were entirely asymptomatic. They concluded that the symptoms of PCS are unlikely to be related to increased duodeno-gastric reflux after surgery. ${ }^{7}$

Combined MII and pH monitoring (MII-pH) allows more comprehensive characterization of reflux episodes to include evaluation of the physical nature (liquid/gas/ mixed), $\mathrm{pH}$ (acid/ weakly acid/ non-acid), proximal extent, direction and the duration of reflux event. ${ }^{22}$ This method has been shown to achieve the highest sensitivity for the detection of GER episodes. A study by Uyanikoglu et al using impedance $\mathrm{pH}$ monitoring showed that alkaline reflux decreased, but acid reflux increased after cholecystectomy. ${ }^{23}$ This is the only study which has used combined MII and $\mathrm{pH}$ monitoring (MII-pH) to study the effect of laparoscopic cholecystectomy on gastroesophageal reflux.

In our study, we found that patients of gallstone disease undergoing laparoscopic cholecystectomy did not have statistically significant changes in basal LES pressure $(\mathrm{p}=0.103)$ and percentage LES relaxation $(\mathrm{p}=0.152)$ after surgery, compared to preoperative values. The changes in the acid reflux characteristics (i.e. acid exposure time, percentage acid exposure time and number of acid reflux episodes) and non-acid reflux characteristics (i.e. non-acid exposure time, percentage nonacid exposure time and number of non-acid reflux episodes) were found to be statistically insignificant. The physical nature of refluxate was also studied for number of liquid, gaseous and mixed reflux episodes and it was found that there were no significant changes in the physical nature of reflux episodes postoperatively $(\mathrm{p}=0.228$ and $\mathrm{p}=0.203$ ). There was a statistically significant decrease in the total number of proximally extending acid reflux episodes after cholecystectomy ( $\mathrm{p}=0.003)$. However, the changes in proximally extending non-acid reflux episodes $(\mathrm{p}=0.256)$ and total proximally extending reflux episodes (acid and non-acid combined, $\mathrm{p}=0.294$ ) were not found to be statistically significant. Also, the total number of reflux episodes (proximal and distal acid and non-acid combined) did not show any statistically significant change $(\mathrm{p}=0.141)$. We also compared the changes in DeMeester's acid reflux composite score. ${ }^{24}$ It was observed that there was an increase in the DeMeester's score from a mean value of 4.93 preoperatively to a mean value of 6.12 postoperatively which was statistically significant ( $\mathrm{p}=0.041)$. However, the increase in DeMeester's score postoperatively was not considered to be not clinically significant as the score increased to a mean value of 6.12 which is less than the normal value of DeMeester's score (i.e. <14.7). The findings of our study suggest that there are no significant changes in gastroesophageal reflux (acid or non-acid) after laparoscopic cholecystectomy. Results of our study suggest that cholecystectomy itself may not be the cause of GER. A more conclusive study would be to compare the patients of PCS with control group of asymptomatic patients after cholecystectomy. As only four patients developed symptoms of reflux, it was not possible to compare with the asymptomatic control group. 


\section{References}

1. Calland JF, Tanaka K, Foley E, Bovbjerg VE, Markey DW, Blome $\mathrm{S}$, et al. Outpatient laparoscopic cholecystectomy: patient outcomes after implementation of a clinical pathway. Ann Surg. 2001;233:704-15.

2. Girometti R, Brondani G, Cereser L, Como G, Del Pin M, Bazzocchi M, et al. Post-cholecystectomy syndrome: spectrum of biliary findings at magnetic resonance cholangiopancreatography. Br J Radiol. 2010;83:351-61.

3. Jaunoo SS, Mohandas S, Almond LM. Postcholecystectomy syndrome (PCS). Int J Surg. 2010;8:15-7.

4. Kunsch S, Neesse A, Huth J, Steinkamp M, Klaus J, Adler G, et al. Increased Duodeno-Gastro-Esophageal Reflux (DGER) in symptomatic GERD patients with a history of cholecystectomy. Z Gastroenterol. 2009;47:744-8.

5. Passaro U, Vasapollo L, Carnevale L, Corsini F, Marano S, Piraino A, et al. [Duodeno-gastric reflux in gallbladder stones and after laparotomic cholecystectomy]. Minerva Chir. 2001;56:139-46.

6. Lin OS, Kozarek RA, Arai A, Gan SI, Gluck M, Jiranek GC, et al. The association between cholecystectomy and gastroesophageal reflux symptoms: a prospective controlled study. Ann Surg. 2010;251:40-5.

7. Manifold DK, Anggiansah A, Owen WJ. Effect of cholecystectomy on gastroesophageal and duodenogastric reflux. Am J Gastroenterol. 2000;95:2746-50.

8. Silny J. Intraluminal multiple electrical impedance procedure for measurement of gastrointestinal motility. J Gastrointest Motil. 1991;3:151-62.

9. Namasivayam V, Arora AS, Murray JA. Weakly acidic reflux. Dis Esophagus. 2011;24:56-62.

10. Karamanolis G, Kotsalidis G, Triantafyllou K, Polymeros D, Gaglia A, Fessatou S, et al. Yield of combined impedance-pH monitoring for refractory reflux symptoms in clinical practice. $J$ Neurogastroenterol Motil. 2011;17:158-63.

11. Sifrim D, Holloway R, Silny J, Xin Z, Tack J, Lerut A, et al. Acid, nonacid, and gas reflux in patients with gastroesophageal reflux disease during ambulatory 24-hour $\mathrm{pH}$-impedance recordings. Gastroenterology. 2001;120:1588-98.

12. Womack NA, Crider RL. The Persistence of Symptoms Following
Cholecystectomy. Ann Surg. 1947;126:31-55.

13. Kusano M, Shimoyama Y, Sugimoto S, Kawamura O, Maeda M, Minashi K, et al. Development and evaluation of FSSG: frequency scale for the symptoms of GERD. J Gastroenterol. 2004;39:888-91.

14. Kung RD, Cai AW, Brown JM, Gamboa AM, Cai Q. The postcholecystectomy syndrome: a review of etiology and current approaches to management. Gastroenterol Insights. 2012;4:1.

15. Ahmad BN, Ahmad WN, Aalam WK, Ahmad SM, Hussain KS. Duodenogastric reflux, an important cause of post cholecystectomy symptoms. JK-Practitioner. 2003;10:188-90.

16. Aydýn S, Akýn ML, Karakaya M, et al. Alkaline reflux gastritis and problems of diagnosis. Çaðdap Cerrahi Dergisi. 1997;11:36-9.

17. Bagaria D, Kaman L, Roger E, Dahyia D, Singh R, Bhattacharya A. Effect of laparoscopic cholecystectomy on gastric emptying and dyspepsia. Surg Endosc. 2013;27:3116-20.

18. Zullo A, Rinaldi V, Hassan C, Lauria V, Attili AF. Gastric pathology in cholecystectomy patients: role of Helicobacter pylori and bile reflux. J Clin Gastroenterol. 1998;27:335-8.

19. Caldwell MT, McDermott M, Jazrawi S, O’Dowd G, Byrne PJ, Walsh TN, et al. Helicobacter pylori infection increases following cholecystectomy. Ir J Med Sci. 1995;164:52-5.

20. Shay S, Tutuian R, Sifrim D, Vela M, Wise J, Balaji N, et al. Twenty-four hour ambulatory simultaneous impedance and $\mathrm{pH}$ monitoring: a multicenter report of normal values from 60 healthy volunteers. Am J Gastroenterol. 2004;99:1037-43.

21. Stefanescu G, Balan G, Stanciu C. [The relationship between bile reflux and symptoms in patients with gallstones before and after cholecystectomy]. Rev Med Chir Soc Med Nat Iasi. 2009;113:698-703.

22. Karoui S, Ben Temime H, Serghini M, Zouiten L, Boubaker J, Filali A. [24-hour esophageal impedance-ph monitoring: technical aspects, indications and results]. Tunis Med. 2012;90:351-6.

23. Uyanikoglu A, Akyuz F, Ermis F, Arici S, Bas G, Cakirca M, et al. Does Cholecystectomy Increase the Esophageal Alkaline Reflux? Evaluation by Impedance-pH Technique. J Neurogastroenterol Motil. 2012;18:187-93.

24. Johnson LF, Demeester TR. Twenty-four-hour $\mathrm{pH}$ monitoring of the distal esophagus. A quantitative measure of gastroesophageal reflux. Am J Gastroenterol. 1974;62:325-32. 